OPEN ACCESS

Edited by:

Alex V. Chaves,

University of Sydney, Australia

Reviewed by:

Simon John Davies,

Harper Adams University,

United Kingdom

Zhen-Yu Du,

East China Normal University, China

Mauro Vasconi

Council for Agricultural and

Economics Research, Italy

*Correspondence:

Junyan Jin

jinjunyan@ihb.ac.cn

Specialty section

This article was submitted to Animal Nutrition and Metabolism,

a section of the journal

Frontiers in Veterinary Science

Received: 08 March 2019

Accepted: 13 May 2019

Published: 29 May 2019

Citation:

Li H, XuW, Jin J, Zhu X, Yang Y Han D, Liu H and Xie S (2019) Effects

of Dietary Carbohydrate and Lipid

Concentrations on Growth

Performance, Feed Utilization, Glucose, and Lipid Metabolism in Two

Strains of Gibel Carp.

Front. Vet. Sci. 6:165

doi: 10.3389/fvets.2019.00165

\section{Effects of Dietary Carbohydrate and Lipid Concentrations on Growth Performance, Feed Utilization, Glucose, and Lipid Metabolism in Two Strains of Gibel Carp}

\author{
Hongyan $\mathrm{Li}^{1,2}$, Wenjie X ${ }^{1}$, Junyan Jin ${ }^{1 *}$, Xiaoming Zhu ${ }^{1}$, Yunxia Yang ${ }^{1}$, Dong Han ${ }^{1}$, \\ Haokun Liu ${ }^{1}$ and Shouqi Xie ${ }^{1}$
}

${ }^{1}$ State Key Laboratory of Freshwater Ecology and Biotechnology, Institute of Hydrobiology, Chinese Academy of Sciences, Wuhan, China, ${ }^{2}$ College of Advanced Agricultural Sciences, University of Chinese Academy of Sciences, Beijing, China

To test the hypothesis that effects of dietary carbohydrate and lipid concentrations on growth performance, feeding utilization, glucose and lipid metabolism in gibel carp A strain may be differ from $\mathrm{F}$ strain, these two strain of gibel carp were fed with one of three different isonitrogenous diets: HCLL (45\% carbohydrate, 2\% lipid), MCML (30\% carbohydrate, $8 \%$ lipid), or LCHL (15\% carbohydrate, 14\% lipid). After 8 weeks, the HCLL-fed fish had the highest hepatosomatic index, hepatic crude lipid levels, and triglyceride levels and lipid retention efficiency. Enhanced lipogenesis and lipid uptake potential were observed in fish fed HCLL and MCML diets. Moreover, increases in glucose transport (glut2, $P=0.003$ ) and glycolysis ( $g k, P=0.012 ; 6 p f k, P=0.005$ ) in livers of both strains were induced by the high-carbohydrate diet. Genotype-specific effect was identified on plasma lipid content. Plasma triglyceride levels were also greater in the F strain than in the A strain. Furthermore, the F strain had higher levels of fatty acid $\beta$-oxidation and glycolysis compared with the A strain. Nutrient retention was affected $(P<0.05)$ by the interaction between genotype and diet, implied dietary carbohydrate played a vital role in lipid accumulation in gibel carp. As dietary lipids increased, the $\mathrm{F}$ strain exhibited better feed utilization and a higher PRE than the A strain. However, the A strain had better growth performance. Overall, the F strain had better glucose uptake, glycolysis potential, and lipid utilization ability than the A strain.

Keywords: carbohydrate, lipid, nutrient metabolism, gibel carp, strain

\section{INTRODUCTION}

Dietary protein is the most expensive ingredient in manufactured fish food, accounting for more than $60 \%$ of the total production cost (1). Fishmeal is considered an ideal protein for aquatic feeds (1). However, fishmeal resources are finite, and fishmeal prices have recently increased as wild fishery populations have declined due to overfishing (2). Therefore, dietary lipids and carbohydrates are of increasing importance to aquaculture, as these nutrients are used as non-protein energy sources in fish feeds and therefore reduce protein requirements (3-5). 
Carbohydrate is the least expensive and most readily-available source of dietary energy for aquatic feeds $(3,6)$. Feeds with proper levels of carbohydrate are more efficiently pelletized, reduce the catabolism of proteins and lipids for energy, and provide metabolites for biological syntheses $(7,8)$. However, fish feeds with an overabundance of dietary carbohydrate may lead to unwanted fat depositions, suppressed immune function, and reduced health $(9-11)$. Dietary lipids are important for fish growth and development as they provide energy, supply essential fatty acids, and act as vectors for fat-soluble vitamins $(12,13)$. However, suboptimal and/or excess levels of dietary lipids may have adverse effects on fish growth and immunity $(10,14,15)$. Importantly, dietary lipid and carbohydrate could affect utilization of each other in fish as lipid could be converted to glucose via gluconeogenesis and glucose could be deposited as lipids in tissues (16). Therefore, determination of the optimal relative levels of carbohydrates and lipids in fish feeds is of great significance to aquaculture.

Fish growth performance and metabolic efficiency vary depending on the dietary carbohydrate and lipid levels (1719). Any imbalance in the supply of non-protein energy sources may negatively affect fish growth, conversion efficiency, nutrient retention, and body composition (20). Many previous studies have separately investigated the effects of dietary carbohydrate and lipids on fish physiology $(15,21-23)$. Until now, the interactions between carbohydrate and lipid levels have been investigated in a few fish species, including red drum (Sciaenops ocellatus) (24), rainbow trout (Oncorhynchus mykiss) (17) and blunt snout bream (Megalobrama amblycephala) (18). However, most studies primarily focused on determining the optimal carbohydrate-to-lipid ratio for growth $(9,16,19)$. The effects of different dietary carbohydrate and lipid levels on the molecular glucose and lipid metabolisms in fish have rarely been investigated.

The efficiency of carbohydrate and lipid utilization differs among fish species and genotypes, as does the regulation of the glucose and lipid metabolisms. Previous studies have shown that carbohydrate utilization varies in different strains of salmonids (Oncorhynchus mykiss) (25, 26). For example, lipids were metabolized differently in two lines of rainbow trout (Oncorhynchus mykiss, Walbaum 1792) divergently selected for muscle fat content: one line ("F") more effectively stored excess glucose and more efficiently bioconverted fatty acids in the intestine than did the other line ("L") $(27,28)$. Different lipid sources also induced genotype-specific effects in two lines of Atlantic salmon (Salmo salar): the transcriptional expression levels of genes associated with the lipid metabolism ( $p$ par $\alpha$, $p \operatorname{par} \beta$, and srebp-1) decreased in the "lean" strain fed vegetable oil (29). Thus, the molecular metabolic response to variations in the dietary carbohydrate and lipid levels might differ among fish strains.

Gibel carp (Carassius gibelio), an omnivorous freshwater fish, is widely cultivated in China due to its high economic value (30, 31). Gibel carp reproduce both sexually and asexually (32). Gibel carp eggs are activated by heterospecific sperm (gynogenesis), producing all-female strains of offspring $(32,33)$. The CAS III (A) strain, which grows rapidly, is the most commonly cultured gibel carp strain in China, accounting for $\sim 70 \%$ of all gibel carp produced $(31,34)$. Strain CAS V (F), a relatively new strain, has higher disease resistance and faster growth than the A strain (34). Previous studies have shown that insulin treatment differently affected the glucose and lipid metabolisms in two strains (A strain and DT strain) of gibel carp (31). And the DT cleared excess blood glucose more quickly than did the A strain in a glucose tolerance test (35). In addition, gibel carp displayed different priorities and sensibilities in the mobilization of energy reserves (36). Thus, we put forward the hypothesis that the effects of dietary carbohydrate and lipid concentrations on growth performance, feed utilization, glucose, and lipid metabolism could be different between $\mathrm{A}$ strain and $\mathrm{F}$ strain. Therefore, in this study, A strain and F strain were fed one of three different isonitrogenous diets: HCLL (High Carbohydrate Low Lipid, 45\% carbohydrate, 2\% lipid), MCML (Medium Carbohydrate Medium Lipid, 30\% carbohydrate, $8 \%$ lipid), or LCHL (Low Carbohydrate High Lipid, 15\% carbohydrate, 14\% lipid). Growth performance, feed utilization, gene expression and enzyme activity involved in glucose and lipid metabolism were compared between these two strains among the three diets. Then, any genotype $\times$ diet interactions were assessed.

\section{MATERIALS AND METHODS}

\section{Experimental Diets}

Three isonitrogenous (32\% crude protein) experimental diets were formulated, each containing different proportions of carbohydrates and lipids: HCLL (45\% carbohydrate and 2\% lipid), MCML (30\% carbohydrate and $8 \%$ lipid), and LCHL (15\% carbohydrate and $14 \%$ lipid). The dietary protein was provided by white fishmeal and casein. Cornstarch was used as the carbohydrate source; fish oil and soybean oil (in equal amounts) were used as the lipid source (Table 1). All of the ingredients were well ground, fully mixed, and then pelleted using a granulator (SLP-45, Fishery Mechanical Facility Research Institute, Shanghai, China). Pellets were dried in an oven at $50^{\circ} \mathrm{C}$ and stored at $4^{\circ} \mathrm{C}$.Fatty acid compositions of the experimental diets were presented in Table 2.

\section{Fish and Feeding Trial}

Two strains of juvenile gibel carp (Carassius gibelio) were obtained from the Institute of Hydrobiology, Chinese Academy of Sciences (Wuhan, Hubei, China): A strain (initial body weight: $3.01 \pm 0.02 \mathrm{~g}$ ) and F strain (initial body weight: $6.20 \pm 0.00 \mathrm{~g}$ ). All fish were acclimated in a fiberglass tank in an indoor rearing system for 2 weeks prior to experimentation and were fed a balanced mix of the experimental diets three times per day. At the beginning of the experiment, all fish were fasted for $24 \mathrm{~h}$. Then fish were randomly allocated among the three dietary groups, with triplicate tanks per group and 30 juveniles per tank. Fish were fed to apparent satiation three times daily (at 08:30, 13:30, and 18:30). The daily feed supplied was recorded, and uneaten feed was collected 20 min after feeding, and dried (37). Throughout the 8-week experiment, water temperature was $25-27^{\circ} \mathrm{C}$, $\mathrm{pH}$ was $6.5-7.0$, dissolved oxygen was $>5 \mathrm{mg} \mathrm{L}^{-1}$, ammonia nitrogen concentration was $<0.5 \mathrm{mg} \mathrm{L}^{-1}$, and light 
TABLE 1 | Formulation and chemical composition of experimental diets.

\begin{tabular}{|c|c|c|c|}
\hline \multirow[t]{2}{*}{ Ingredients (\% dry matter) } & \multicolumn{3}{|c|}{ Diets } \\
\hline & HCLL & MCML & LCHL \\
\hline White fishmeal $^{\mathrm{a}}$ & 15 & 15 & 15 \\
\hline Casein $^{b}$ & 24 & 24 & 24 \\
\hline Fish oil ${ }^{C}$ : soybean oil $(1: 1)$ & 0 & 6 & 12 \\
\hline Corn starch ${ }^{d}$ & 45 & 30 & 15 \\
\hline Vitamin premix & 0.39 & 0.39 & 0.39 \\
\hline Choline chloride & 0.11 & 0.11 & 0.11 \\
\hline Mineral premix ${ }^{\dagger}$ & 5 & 5 & 5 \\
\hline Carboxymethylcellulose sodium & 3 & 3 & 3 \\
\hline Cellulose & 7.5 & 16.5 & 25.5 \\
\hline \multicolumn{4}{|l|}{ CHEMICAL COMPOSITION (\%) } \\
\hline Crude protein & 32.50 & 33.20 & 32.96 \\
\hline Crude lipid & 2.35 & 8.17 & 14.47 \\
\hline Starch & 38.59 & 24.91 & 13.88 \\
\hline Ash & 6.10 & 6.32 & 6.78 \\
\hline Gross energy (kJ/g) & 18.14 & 19.50 & 20.86 \\
\hline \multicolumn{4}{|c|}{ 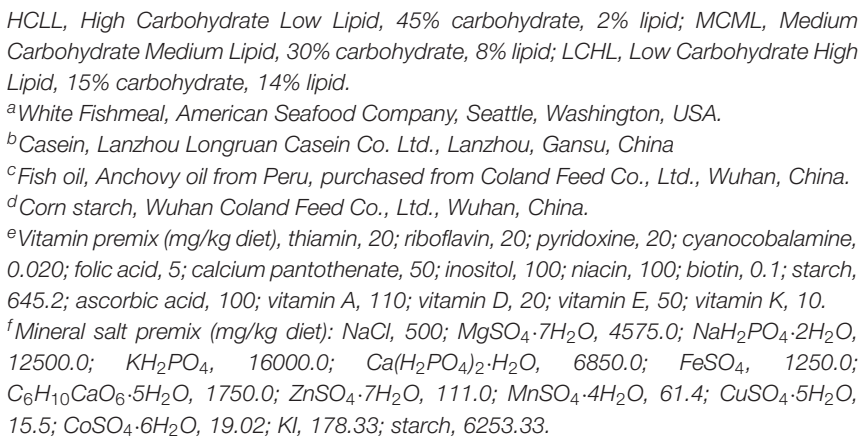 } \\
\hline
\end{tabular}

intensity was $2.21-2.95 \mu \mathrm{mols}^{-1} \mathrm{~m}^{-2}$, with a photoperiod of 12 L:12 D. The experimental protocol was approved by the ethics committee of the Institute of Hydrobiology, Chinese Academy of Sciences.

\section{Sample Collection}

At $8 \mathrm{~h}$ after the final feeding, fish were anesthetized in diluted MS-222 (0.06 $\mathrm{g} \mathrm{L}^{-1}$; Sigma, St. Louis, MO, USA), counted, batched-weighed, and sampled. Three fish of both strains at the beginning of the experiment and four fish per tank at the end of the experiment were collected and stored at $-20^{\circ} \mathrm{C}$ for body composition analysis. Three fish per tank were randomly selected for the measurement of body weight and body length. The viscera and hepatopancreas were removed from these fish and weighted to calculate conditional factor (CF), viscerosomatic index (VSI), and hepatosomatic index (HSI). Blood samples were collected from an additional two randomly selected fish per tank, using syringes rinsed with heparin sodium (0.2\%). After centrifugation at $3,000 \mathrm{~g}$ for $10 \mathrm{~min}$, each plasma sample was immediately frozen and held at $-80^{\circ} \mathrm{C}$ until analysis. The liver and dorsal muscle from these fish were immediately removed on ice, frozen in liquid nitrogen, and stored at $-80^{\circ} \mathrm{C}$ for posterior analysis.
TABLE 2 | Fatty acid composition (\% of total fatty acids) of the experimental diets.

\begin{tabular}{|c|c|c|c|}
\hline \multirow[t]{2}{*}{ Fatty acid (\%) } & \multicolumn{3}{|c|}{ Diets } \\
\hline & HCLL & MCML & LCHL \\
\hline C14:0 & 3.27 & 4.71 & 6.48 \\
\hline C15:0 & 0.36 & 0.46 & 0.20 \\
\hline C16:0 & 13.44 & 11.05 & 14.24 \\
\hline C17:0 & 0.28 & 0.35 & 0.39 \\
\hline C18:0 & 6.40 & 5.85 & 4.52 \\
\hline$\Sigma \mathrm{SFA}^{\mathrm{a}}$ & 23.75 & 22.43 & 25.83 \\
\hline C16:1n-9 & 5.71 & 4.48 & 6.97 \\
\hline C18:1n-9 & 36.27 & 26.21 & 19.44 \\
\hline C20:1n-9 & 3.54 & 2.63 & 1.77 \\
\hline C22:1n-9 & 2.71 & 4.04 & 1.82 \\
\hline$\Sigma$ MUFA $^{\mathrm{b}}$ & 48.23 & 37.35 & 30.00 \\
\hline C18:2n-6 & 15.18 & 24.00 & 21.31 \\
\hline C18:3n-6 & 0.23 & 0.14 & 0.14 \\
\hline C20:2n-6 & 0.43 & 0.35 & 0.41 \\
\hline C20:4n-6 & 0.60 & 0.77 & 0.49 \\
\hline$\Sigma \mathrm{n}-6$ PUFA ${ }^{\mathrm{C}}$ & 16.43 & 25.26 & 22.36 \\
\hline C18:3n-3 & 0.76 & 3.37 & 2.51 \\
\hline C20:5n-3 & 2.69 & 4.31 & 3.56 \\
\hline C22:6n-3 & 4.72 & 5.76 & 6.35 \\
\hline$\Sigma$ n-3 PUFA & 8.17 & 13.43 & 12.42 \\
\hline n-3/n-6 PUFA & 0.50 & 0.53 & 0.56 \\
\hline
\end{tabular}

HCLL, High Carbohydrate Low Lipid, 45\% carbohydrate, 2\% lipid; MCML, Medium Carbohydrate Medium Lipid, 30\% carbohydrate, 8\% lipid; LCHL, Low Carbohydrate High Lipid, $15 \%$ carbohydrate, $14 \%$ lipid.

a SFA, saturated fatty acids.

${ }^{b}$ MUFA, monounsaturated fatty acids.

${ }^{c}$ PUFA, polyunsaturated fatty acids.

\section{Chemical Analysis}

Proximate compositions of the feeds and fish samples were analyzed following AOAC methods (38). Moisture content was determined by oven (Heating and Drying Oven, XMTD-8222, Jinghong, Shanghai, China) drying at $105^{\circ} \mathrm{C}$ to constant weight (Method 934.01, AOAO 2003). Ash content was determined via combustion in a muffle furnace (Muffle furnace, Yingshan, Hubei, China) at $550^{\circ} \mathrm{C}$ to a constant weight [Method 942.05, (38)]. Crude protein content $(\mathrm{N} \times 6.25)$ was determined after acid digestion with the Kjeldahl method [Method 990.03, (38)], using a 4,800 Kjeltec Analyzer Unit (FOSS Tecator, Haganas, Sweden). Crude lipid content was determined using ether extraction in a Soxtec system (Soxtec System HT6, Tecator, Haganas, Sweden), with diethyl ether as the extraction liquid [Method 920.39, (38)]. The starch content of the diet was measured using the commercial starch content kit (A148-1-1, Jiancheng Bioengineering Institute, Nanjing, China). The liver and muscle were freeze-dried in a freeze dryer (Christ ALPHA 1-4 LD plus, Germany), and the crude lipid contents of the freeze-dried organs were determined using ether extraction in a Soxtec system (Soxtec System HT6, Tecator, Haganas, Sweden), with diethyl ether as the extraction liquid. For the measurement of fatty acid compositions, lipids of the experimental diets were extracted with a chloroform:methanol $(2: 1 \mathrm{v} / \mathrm{v})$ mixture 
as described by Folch et al. (39). Fatty acid methyl esters were obtained by transmethylation as described by Christie (40). The fatty acid composition of diets was determined using the gas chromatography (7890A-5975C, Agilents Technologies Inc., Santa Clara, CA, USA). An HP-88 capillary column $(60 \mathrm{~m} \times$ $250 \mu \mathrm{m} \times 0.2 \mu \mathrm{m}$, Agilent 112-8867) was used to provide the fatty acid separation. The column was set at a constant flow rate of $1 \mathrm{~mL} / \mathrm{min}$ using helium as carrier gas, and the septum purge flow was $3 \mathrm{~mL} / \mathrm{min}$. The injection volume was $1.0 \mu \mathrm{L}$ in splitless mode with the split ratio at 10:1. The temperature of injector, ion source, and transfer line was set at $280{ }^{\circ} \mathrm{C}, 230{ }^{\circ} \mathrm{C}$ and 230 ${ }^{\circ} \mathrm{C}$, respectively. The total runtime was $46 \mathrm{~min}$ and the oven temperature was programed as follows: the initial temperature was $100{ }^{\circ} \mathrm{C}$ for $5 \mathrm{~min}$, then increased to $230^{\circ} \mathrm{C}$ (for $15 \mathrm{~min}$ ) at $5^{\circ} \mathrm{C} / \mathrm{min}$. Fatty acids in the diet samples were calculated by the standard curves and fatty acid composition was expressed as percentage of total fatty acids.

Plasma glucose, non-esterified fatty acids (NEFAs), triglycerides, and total cholesterol content were determined using commercial kits (Fujifilm, Wako Pure Chemical Corporation, Osaka, Japan), following the manufacturer's instructions. Plasma low-density lipoprotein cholesterol (LDLC) and high-density lipoprotein cholesterol (HDL-C) were measured using commercial kits (A113-1 and A112-1; Jiancheng
Bioengineering Institute, Nanjing, China). The activity levels of several hepatic enzymes [i.e., hexokinase (HK), pyruvate kinase (PK), phosphoenolpyruvate carboxykinase (PEPCK), lipoprotein lipase (LPL) and hepatic lipase (HL)] were determined using commercially kits (Jiancheng Bioengineering Institute, Nanjing, China). The enzyme levels of acetyl-CoA carboxylase (ACC) and fatty acid synthase (FAS) were determined using commercially available ELISA kit (Jiancheng Bioengineering Institute, Nanjing, China).

\section{Gene Expression Analysis}

Total RNAs were extracted from the hepatopancreas and muscle tissue using TRIzol reagent (Invitrogen, Carlsbad, California, USA), and cDNA was reverse transcribed using an M-MLV First-Strand Synthesis Kit (Invitrogen, Shanghai, China), following the manufacturer's instructions. Quantitative reverse transcription-polymerase chain reaction (RT-PCR) was performed on a LightCycler 480 II (Roche Diagnostics, Basel, Switzerland), using SYBR Green I Master Mix (Roche Diagnostics, Indianapolis, IN, USA). The expression levels of genes associated with the glucose or lipid metabolisms were determined using quantitative real-time RT-PCR. Specific RT-PCR primers for ppara (Peroxisome proliferator-activated receptor alpha; F: GTTCTCAGAAGTGTTTGCGTCC; R: GC

TABLE 3 | Effects of dietary carbohydrate and lipid levels on growth performance, feed utilization, and morphological indices in two strains of gibel carp.

\begin{tabular}{|c|c|c|c|c|c|c|c|c|c|c|}
\hline Diet & Strain & IBW $(g)^{1}$ & FBW $(g)^{2}$ & $\mathrm{FI}(\mathrm{g} / \mathrm{fish})^{3}$ & FR $(\% B W / d)^{4}$ & FE $(\%)^{5}$ & SGR (\% /d) ${ }^{6}$ & CF $\left(g / \mathrm{cm}^{3}\right)^{7}$ & HSI (\%) ${ }^{8}$ & VSI $(\%)^{9}$ \\
\hline HCLL & A & $3.02 \pm 0.02$ & $18.24 \pm 0.42$ & $24.13 \pm 0.46$ & $4.06 \pm 0.06^{e}$ & $63.04 \pm 0.90^{\mathrm{a}}$ & $3.21 \pm 0.05$ & $3.37 \pm 0.14$ & $5.46 \pm 0.18$ & $14.36 \pm 0.22$ \\
\hline & $\mathrm{F}$ & $6.19 \pm 0.00$ & $25.55 \pm 1.44$ & $29.60 \pm 1.72$ & $3.33 \pm 0.03^{c}$ & $65.25 \pm 1.27^{\mathrm{a}}$ & $2.52 \pm 0.11$ & $3.20 \pm 0.17$ & $6.24 \pm 0.16$ & $15.15 \pm 0.09$ \\
\hline & $\mathrm{F}$ & $6.21 \pm 0.01$ & $29.78 \pm 1.37$ & $30.29 \pm 1.11$ & $3.01 \pm 0.07^{b}$ & $77.69 \pm 1.89^{\mathrm{C}}$ & $2.79 \pm 0.09$ & $3.53 \pm 0.08$ & $7.03 \pm 0.63$ & $15.73 \pm 0.57$ \\
\hline \multirow[t]{2}{*}{ LCHL } & A & $3.01 \pm 0.02$ & $17.43 \pm 1.23$ & $22.50 \pm 1.45$ & $3.93 \pm 0.11^{\mathrm{e}}$ & $63.94 \pm 2.04^{a}$ & $3.13 \pm 0.14$ & $3.51 \pm 0.06$ & $4.60 \pm 0.74$ & $15.70 \pm 0.91$ \\
\hline & $\mathrm{F}$ & $6.21 \pm 0.01$ & $28.78 \pm 0.86$ & $26.73 \pm 0.91$ & $2.73 \pm 0.06^{a}$ & $84.46 \pm 0.28^{d}$ & $2.74 \pm 0.05$ & $3.26 \pm 0.18$ & $4.85 \pm 0.37$ & $15.55 \pm 0.24$ \\
\hline \multicolumn{11}{|c|}{ Diet } \\
\hline \multicolumn{2}{|c|}{ HCLL } & & & & & & & \multicolumn{2}{|r|}{$5.85 \pm 0.21^{Y}$} & \\
\hline \multicolumn{2}{|c|}{ MCML } & & & & & & & & \\
\hline \multicolumn{2}{|c|}{ LCHL } & & & & & & & & $\begin{array}{l}6.17 \pm 0.51 \\
4.73 \pm 0.37^{X}\end{array}$ & \\
\hline \multicolumn{11}{|c|}{ Strain } \\
\hline \multicolumn{2}{|c|}{ A } & $3.01 \pm 0.01^{\mathrm{A}}$ & $18.31 \pm 0.46^{A}$ & $23.17 \pm 0.65^{A}$ & & & $3.22 \pm 0.05^{\mathrm{B}}$ & & $5.12 \pm 0.27^{A}$ & \\
\hline & $S \times D$ & 0.481 & 0.162 & 0.395 & $<0.001$ & $<0.001$ & 0.266 & 0.387 & 0.309 & 0.659 \\
\hline
\end{tabular}

HCLL, High Carbohydrate Low Lipid, 45\% carbohydrate, 2\% lipid; MCML, Medium Carbohydrate Medium Lipid, 30\% carbohydrate, 8\% lipid; LCHL, Low Carbohydrate High Lipid, 15\% carbohydrate, $14 \%$ lipid.

${ }^{1}$ IBW, Initial body weight.

${ }^{2} \mathrm{FBW}$, Final body weight.

${ }^{3}$ Feed intake.

${ }^{4}$ FR, Feed rate.

${ }^{5} F E$, Feed efficiency.

${ }^{6} S G R$, Specific growth rate.

${ }^{7} \mathrm{CF}$, Condition factor.

${ }^{8} \mathrm{HSI}$, Hepatosomatic index.

${ }^{9} \mathrm{VSI}$, Viscerosomatic index.

Values are expressed as means \pm s.e.m. of three replicates. Significant differences among all groups are indicated by different superscripts on each column $(a, b$, or $c)(P<0.05)$. The uppercase letters $A$ and $B$ represent significant differences between strains; and the uppercase letters $X, Y$, and $Z$ represent significant differences among diets $(P<0.05)$. 
ACTCCATAGTGGAAACCTGA; Genbank accession number: MK160995) and atgl (Adipose triglyceride lipase; F: GTGTACT GTGGCCTGATACCT; R: GCGCAGCTCATGGATGTTGGT; Genbank accession number: MK071344) were designed for this study; remaining primers were from $\mathrm{Li}$ et al. (36). The mRNA expression levels in the hepatopancreas and the muscle tissues were calculated as fold-change in expression relative to the housekeeping gene, $\beta$-actin. Gene expression levels were analyzed in six fish $(n=6)$. Results were calculated based on the Pfaffl mathematical model (41).

\section{Calculations and Statistical Analysis}

The following variables were calculated:

IBW: Initial body weight;

FBW: Final body weight;

Feed intake (FI, g/fish) = dry feed intake / number of fish;

Feed rate $(\mathrm{FR}, \% \mathrm{BW} / \mathrm{d})=100 \times$ dry feed intake $/$ [days $\times$ $(\mathrm{IBW}+\mathrm{FBW}) / 2]$;

Feed efficiency $(\mathrm{FE}, \%)=(100 \times$ fresh body weight gain $) /$ dry feed intake;

Specific growth rate $(\mathrm{SGR}, \% / \mathrm{d})=100 \times[\ln ($ final weight $)-$ $\ln$ (initial weight)] /days;

Condition factor $\left(\mathrm{CF}, \mathrm{g} / \mathrm{cm}^{3}\right)=100 \times($ body weight $) /$ (body length) ${ }^{3}$;

Hepatosomatic index $(\mathrm{HSI}, \%)=100 \times$ liver weight $/$ whole body weight;
Viscerosomatic index $($ VSI, \% $)=100 \times$ viscera weight $/$ whole body weight;

Protein retention efficiency $(\mathrm{PRE}, \%)=(100 \times$ body retained protein) / protein intake;

Lipid retention efficiency $(\mathrm{LRE}, \%)=(100 \times$ body retained lipid) / lipid intake.

All of the data were expressed as the mean of all replicates $(n=6) \pm$ the standard error of the mean (s.e.m.). All of the analyses were performed in SPSS (version 22.0; SPSS Inc., Chicago, IL, USA). Taking the different initial body weights of the experimental fish into consideration, a two-way analysis of covariance (ANCOVA) was performed, with initial body weight as a concomitant variable. All of the data were checked for normality and homogeneity of variances using the ShapiroWilk and Leven tests. The linearity of the relationship between the variable and the covariate, and the homogeneity of each regression slope, was determined before running the ANCOVA. Where appropriate, differences between strains or diets were analyzed using one-way ANCOVAs.

\section{RESULTS}

\section{Growth Performance, Feed Utilization, and Fish Morphological Indices}

As shown in Table 3, feed intake was $24.6 \%$ greater $(P<0.001)$ in F strain compared to A strain. We observed interactions between

TABLE 4 | Effects of dietary carbohydrate and lipid levels on body chemical composition, liver and muscle lipid content, and nutrient retention efficiency in two strains of gibel carp.

\begin{tabular}{|c|c|c|c|c|c|c|c|c|c|}
\hline \multirow[t]{2}{*}{ Diet } & \multirow[t]{2}{*}{ Strain } & \multicolumn{3}{|c|}{ Crude lipid content (\%) } & \multirow[t]{2}{*}{ Crude protein (\%) } & \multirow[t]{2}{*}{ Ash (\%) } & \multirow[t]{2}{*}{ Moisture (\%) } & \multirow[t]{2}{*}{ PRE $(\%)^{1}$} & \multirow[t]{2}{*}{ LRE $(\%)^{2}$} \\
\hline & & Fish body & Liver & Muscle & & & & & \\
\hline \multirow[t]{2}{*}{ HCLF } & A & $8.16 \pm 0.41$ & $7.11 \pm 1.07$ & $1.86 \pm 0.15^{\mathrm{a}}$ & $18.04 \pm 0.97$ & $4.02 \pm 0.35$ & $67.71 \pm 2.16$ & $35.24 \pm 2.49^{b}$ & $275.66 \pm 17.05^{d}$ \\
\hline & $\mathrm{F}$ & $8.75 \pm 0.53$ & $7.50 \pm 1.90$ & $2.76 \pm 0.16^{\mathrm{cd}}$ & $16.57 \pm 1.25$ & $3.85 \pm 0.08$ & $68.26 \pm 2.01$ & $33.9 \pm 0.53^{b}$ & $367.09 \pm 17.16^{\mathrm{e}}$ \\
\hline \multirow[t]{2}{*}{ MCMF } & A & $8.90 \pm 0.35$ & $6.26 \pm 0.71$ & $2.89 \pm 0.14^{d}$ & $14.88 \pm 0.19$ & $3.33 \pm 0.10$ & $70.8 \pm 0.51$ & $35.82 \pm 2.45^{b}$ & $95.28 \pm 4.41^{\mathrm{bc}}$ \\
\hline & $\mathrm{F}$ & $9.41 \pm 0.40$ & $6.02 \pm 0.80$ & $2.27 \pm 0.24^{\mathrm{abc}}$ & $14.64 \pm 0.13$ & $3.57 \pm 0.03$ & $69.8 \pm 0.56$ & $38.77 \pm 0.55^{b}$ & $127.37 \pm 5.40^{\mathrm{C}}$ \\
\hline \multirow[t]{2}{*}{ LCHF } & A & $8.71 \pm 0.14$ & $3.87 \pm 0.69$ & $2.51 \pm 0.16^{\mathrm{bcd}}$ & $14.89 \pm 0.12$ & $3.25 \pm 0.04$ & $71.16 \pm 0.32$ & $28.14 \pm 2.49^{a}$ & $41.11 \pm 3.88^{a}$ \\
\hline & $\mathrm{F}$ & $9.03 \pm 0.77$ & $4.35 \pm 0.75$ & $2.07 \pm 0.11^{a b}$ & $15.00 \pm 0.40$ & $3.73 \pm 0.09$ & $69.46 \pm 1.07$ & $45.93 \pm 0.77^{C}$ & $77.53 \pm 3.00^{b}$ \\
\hline \multicolumn{10}{|c|}{ MEANS OF MAIN EFFECT } \\
\hline \multicolumn{10}{|c|}{ Diet } \\
\hline \multicolumn{2}{|c|}{ HCLF } & \multicolumn{3}{|c|}{$7.31 \pm 0.76^{Y}$} & $17.30 \pm 0.78^{Y}$ & $3.93 \pm 0.17^{Y}$ & & & \\
\hline \multicolumn{2}{|c|}{ MCMF } & \multicolumn{3}{|c|}{$6.14 \pm 0.76^{X Y}$} & $14.76 \pm 0.12^{X}$ & $3.45 \pm 0.07^{X}$ & & & \\
\hline \multicolumn{2}{|c|}{ LCHF } & & $4.11 \pm 0.76^{X}$ & & $14.94 \pm 0.19^{X}$ & $3.49 \pm 0.12^{X}$ & & & \\
\hline \multicolumn{10}{|c|}{ Strain } \\
\hline \multicolumn{10}{|c|}{ A } \\
\hline \multicolumn{10}{|c|}{$\mathrm{F}$} \\
\hline \multirow[t]{3}{*}{$P$} & Strain & 0.241 & 0.820 & 0.124 & 0.350 & 0.183 & 0.521 & 0.001 & $<0.001$ \\
\hline & Diet & 0.363 & 0.030 & 0.011 & 0.004 & 0.017 & 0.171 & 0.288 & $<0.001$ \\
\hline & $S \times D$ & 0.956 & 0.940 & 0.009 & 0.492 & 0.154 & 0.691 & $<0.001$ & 0.026 \\
\hline
\end{tabular}

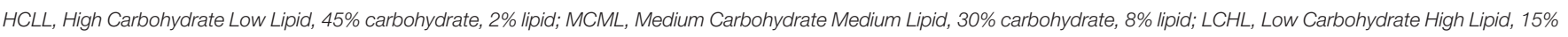
carbohydrate, $14 \%$ lipid.

${ }^{1} P R E$, Protein retention efficiency.

${ }^{2} L R E$, Lipid retention efficiency.

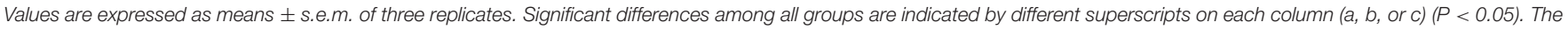
uppercase letters $A$ and $B$ represent significant differences between strains; and the uppercase letters $X, Y$, and $Z$ represent significant differences among diets ( $P<0.05)$. 
genotype and diet with respect to $\mathrm{FR}(P<0.001)$ and FE $(P$ $<0.001)$ (Table 3). The A strain had a higher $(P<0.001)$ FR than the F strain, regardless of the dietary carbohydrate and lipid concentration. In contrast, the FE of the F strain increased with the decreasing concentration of carbohydrate and increasing concentration of lipid. The SGR of the A strain was higher $(P<0.001)$ than that of the $\mathrm{F}$ strain, regardless of diet. No interactions were identified in CF, HSI, or VSI, but the HSI of the $\mathrm{F}$ strain was greater $(P=0.032)$ than that of the A strain irrespective of diet (Table 3). In addition, fish fed the HCLL and MCML diets had higher $(P=0.022)$ HSIs than did the LCHL-fed fish.

\section{Chemical Composition and Nutrient Retention}

No strain $\times$ diet interactions were identified with respect to whole-body crude protein, crude lipid, moisture, or ash content $(P>0.05$; Table 4). However, the dietary carbohydrate and lipid concentration affected crude protein $(P=0.004)$ and ash content $(P=0.017)$ : fish fed the HCLL diet had higher crude protein and ash levels than did the fish fed with the MCML or the LCHL diet, regardless of genotype $(P<0.05)$. In addition, dietary carbohydrate and lipid concentration and genotype had interactive effects on PRE $(P<0.001)$ and LRE $(P=0.026)$. The PRE of the A strain was lowest in fish fed the LCHL diet, while the PRE of the F strain was highest in fish fed the LCHL diet. In both strains, LRE declined $(P<$ 0.001 ) with the decreasing concentration of carbohydrate and increasing concentration of lipid. Fish fed the HCLL diet had higher $(P=0.030)$ hepatic lipid levels than fish fed the LCHL group, irrespective of genotype (Table 4). With the decreasing concentration of carbohydrate and increasing concentration of lipid, muscle lipid contents increased in the A strain and decreased in the F strain (Table 4).

\section{Plasma and Liver Chemical Compositions}

The interactions between strain and dietary carbohydrate and lipid had no effects on levels of plasma glucose, NEFA, total cholesterol, or LDL-C (Table 5). The levels of NEFA and LDL$\mathrm{C}$ in the $\mathrm{F}$ strain were higher $(P<0.05)$ than in the $\mathrm{A}$ strain, while fish fed the LCHL diet had lower levels of LDL-C than fish fed the other two diets, irrespective of genotype $(P<$ 0.05). The interaction between strain and dietary carbohydrate and lipid were identified $(P<0.05)$ on plasma triglycerides and HDL-C content. The F strain had higher triglyceride $(P<$ $0.001)$ and HDL-C levels $(P=0.011)$ than the A strain across all diets, except for HDL-C levels in fish fed the LCHL diet. In the A strain, triglyceride and HDL-C levels did not vary among different dietary carbohydrate and lipid concentration groups. In contrast, triglyceride and HDL-C levels were lowest in the F strain fish fed the LCHL diet. Hepatic triglycerid (TG) and cholesterol levels were affected $(P=0.001)$ by the dietary

TABLE 5 | Effects of dietary carbohydrate and lipid levels on plasma and liver metabolite levels in two strains of gibel carp.

\begin{tabular}{|c|c|c|c|c|c|c|c|c|c|}
\hline \multirow[t]{2}{*}{ Diet } & \multirow[t]{2}{*}{ Strain } & \multicolumn{6}{|c|}{ Plasma } & \multicolumn{2}{|c|}{ Liver } \\
\hline & & $\begin{array}{l}\text { Glucose } \\
\text { (mmol/L) }\end{array}$ & $\begin{array}{l}\text { Triglycerides } \\
\text { (mmol/L) }\end{array}$ & $\begin{array}{c}\text { NEFA } \\
(\mathrm{mEq} / \mathrm{L})^{1}\end{array}$ & $\begin{array}{l}\text { Cholesterol } \\
\text { (mmol/L) }\end{array}$ & $\begin{array}{c}\text { LDL-C } \\
(\mathrm{mmol} / \mathrm{L})^{2}\end{array}$ & $\begin{array}{c}\text { HDL-C } \\
(\mathrm{mmol} / \mathrm{L})^{3}\end{array}$ & $\begin{array}{l}\text { Triglycerides } \\
\text { (mg/g) }\end{array}$ & $\begin{array}{c}\text { Cholesterol } \\
(\mathrm{mg} / \mathrm{g})\end{array}$ \\
\hline \multirow[t]{2}{*}{ HCLL } & A & $4.05 \pm 0.24$ & $3.67 \pm 0.19^{a}$ & $0.30 \pm 0.05$ & $7.14 \pm 0.73$ & $7.84 \pm 0.41$ & $4.46 \pm 0.31^{a}$ & $30.73 \pm 5.23$ & $5.12 \pm 1.02$ \\
\hline & $\mathrm{F}$ & $4.36 \pm 0.22$ & $6.89 \pm 0.70^{C}$ & $0.52 \pm 0.08$ & $9.21 \pm 0.30$ & $9.70 \pm 0.67$ & $6.04 \pm 0.25^{b}$ & $24.06 \pm 3.05$ & $4.32 \pm 1.00$ \\
\hline \multicolumn{2}{|c|}{ MCMLA } & $3.64 \pm 0.54$ & $4.24 \pm 0.28^{\mathrm{ab}}$ & $0.30 \pm 0.08$ & $7.61 \pm 0.78$ & $7.35 \pm 0.71$ & $4.24 \pm 0.13^{a}$ & $11.69 \pm 1.07$ & $1.61 \pm 0.21$ \\
\hline LCHL & $\mathrm{F}$ & $5.54 \pm 0.56$ & $5.3 \pm 0.21^{b}$ & $0.61 \pm 0.08$ & $7.11 \pm 0.17$ & $6.87 \pm 0.65$ & $4.39 \pm 0.77^{a}$ & $8.92 \pm 2.02$ & $1.22 \pm 0.28$ \\
\hline \multicolumn{10}{|c|}{ MEANS OF MAIN EFFECT } \\
\hline \multicolumn{10}{|c|}{ Diet } \\
\hline \multicolumn{2}{|c|}{ HCLL } & & & & & $8.77 \pm 0.47^{Y}$ & & $27.40 \pm 2.11^{Y}$ & $4.72 \pm 0.45^{Y}$ \\
\hline \multicolumn{2}{|c|}{ MCML } & & & & & $8.30 \pm 0.58^{Y}$ & & $13.75 \pm 2.11^{X}$ & $1.96 \pm 0.45^{x}$ \\
\hline \multicolumn{2}{|r|}{$\mathrm{F}$} & & & $0.60 \pm 0.05^{\mathrm{B}}$ & & $8.60 \pm 0.49^{B}$ & & & \\
\hline \multirow[t]{3}{*}{$P$} & Strain & 0.764 & $<0.001$ & $<0.001$ & 0.054 & 0.016 & 0.011 & 0.596 & 0.818 \\
\hline & Diet & 0.385 & 0.648 & 0.618 & 0.121 & 0.010 & 0.375 & 0.001 & 0.001 \\
\hline & $S \times D$ & 0.857 & 0.013 & 0.670 & 0.146 & 0.357 & 0.008 & 0.197 & 0.503 \\
\hline
\end{tabular}

HCLL, High Carbohydrate Low Lipid, 45\% carbohydrate, 2\% lipid; MCML, Medium Carbohydrate Medium Lipid, 30\% carbohydrate, 8\% lipid; LCHL, Low Carbohydrate High Lipid, 15\% carbohydrate, $14 \%$ lipid.

${ }^{1}$ NEFA, nonesterified fatty acids.

${ }^{2}$ LDL-C, low-density lipoprotein cholesterol.

${ }^{3} \mathrm{HDL}-\mathrm{C}$, high-density lipoprotein cholesterol.

Values are expressed as means \pm s.e.m. $(n=6)$. Significant differences among all groups are indicated by different superscripts on each column $(a, b$, or $c)(P<0.05)$. The uppercase letters $A$ and $B$ represent significant differences between strains; and the uppercase letters $X, Y$, and $Z$ represent significant differences among diets $(P<0.05)$. 
A

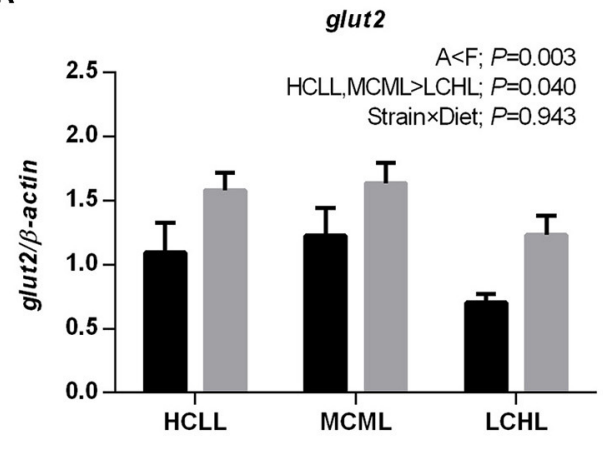

gk

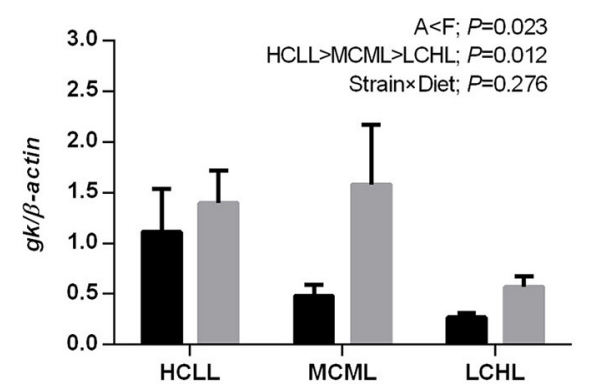

6pfk

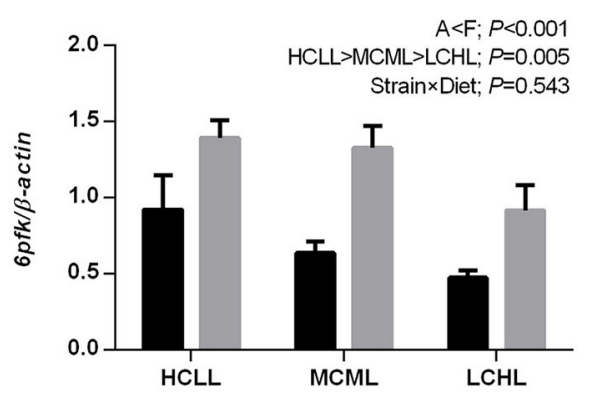

pk

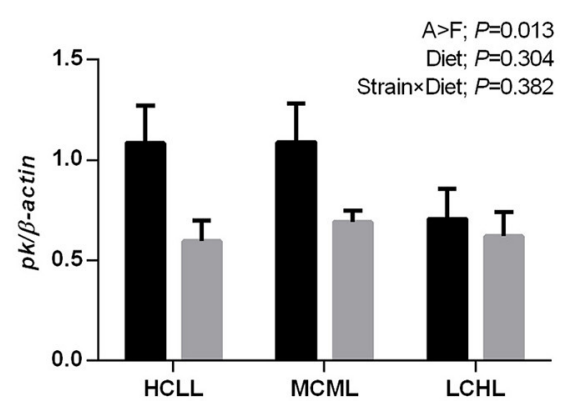

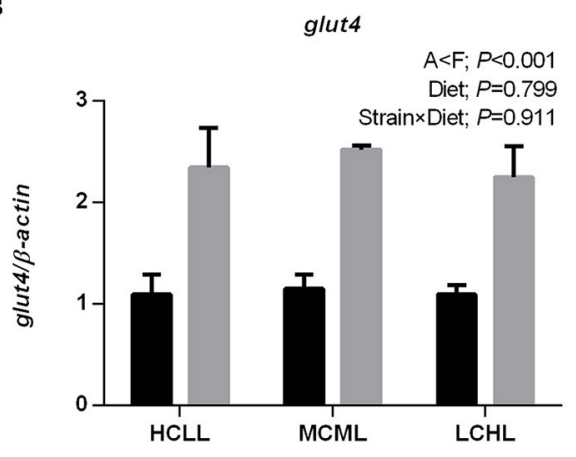
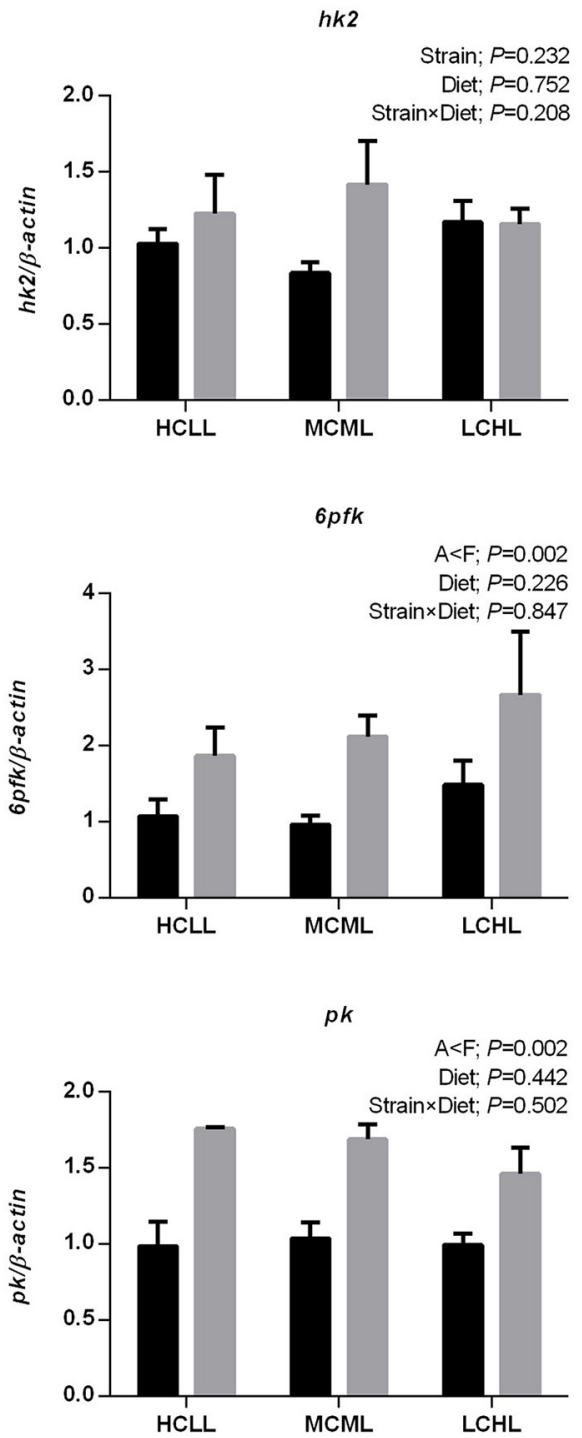

FIGURE 1 | Gene expression levels of selected glucose transporter and glycolytic enzymes in the liver (A) and muscle (B) of the A strain (black bars) and the F strain (gray bars) fed the HCLL (High Carbohydrate Low Lipid, 45\% carbohydrate, 2\% lipid), MCML (Medium Carbohydrate Medium Lipid, 30\% carbohydrate, 8\% lipid), or LCHL (Low Carbohydrate High Lipid, 15\% carbohydrate, 14\% lipid) diet. Measurements were taken $8 \mathrm{~h}$ after the last feeding. Glucose transporter type 2 (g/ut2), glucose transporter type 4 (glut4), glucokinase ( $g k$ ), hexokinase 2 (hk2), 6-phosphofructokinase (6pfk), and pyruvate kinase (pk) mRNA levels were measured using real-time quantitative RT-PCR. Results represent the mean \pm s.e.m $(n=6)$. Significance was determined using a two-way ANOVA $(P<0.05)$, followed by the Student-Newman-Keuls multiple comparison test. 


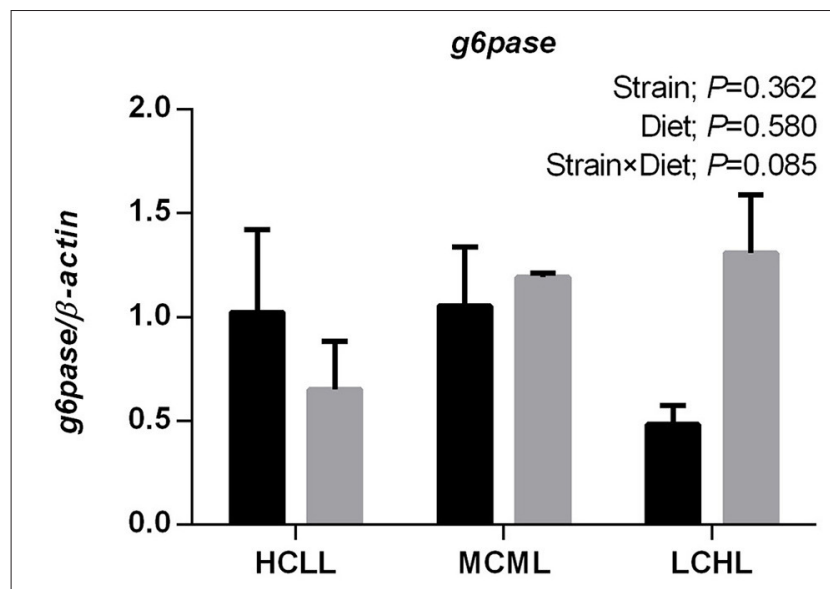

fbpase

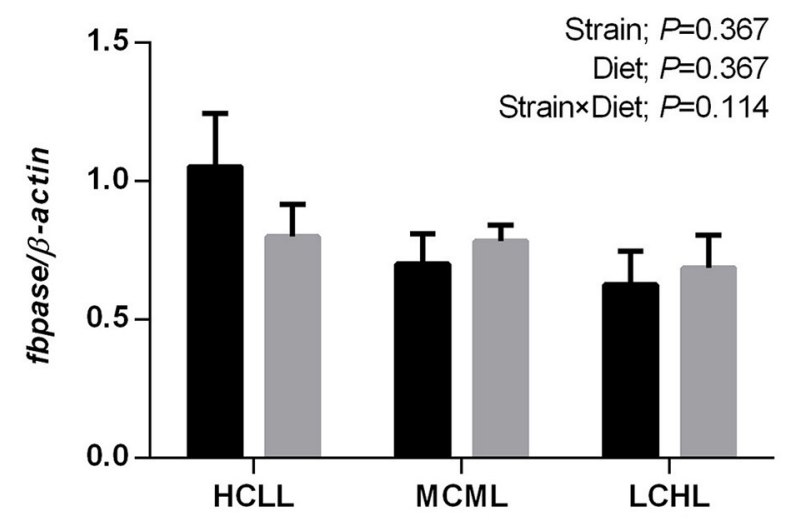

pepck

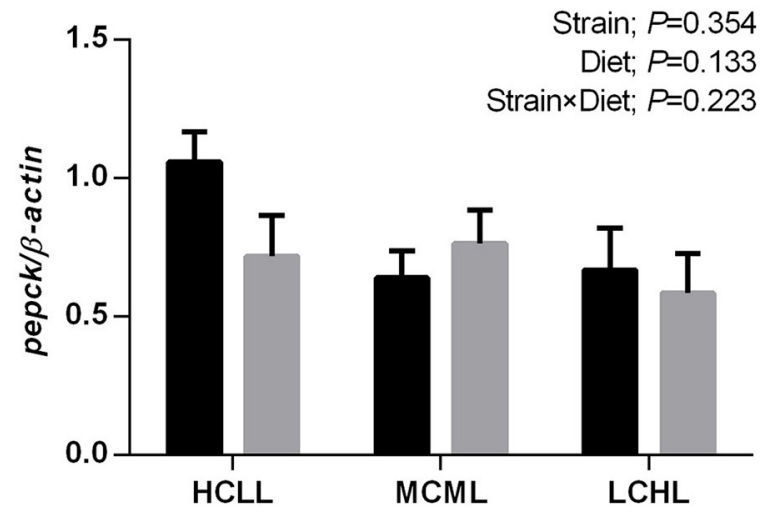

FIGURE 2 | Gene expression levels of selected gluconeogenesis enzymes in the liver of the A strain (black bars) and the F strain (gray bars) fed the HCLL (High Carbohydrate Low Lipid, 45\% carbohydrate, 2\% lipid), MCML (Medium Carbohydrate Medium Lipid, 30\% carbohydrate, 8\% lipid), or LCHL (Low Carbohydrate High Lipid, 15\% carbohydrate, 14\% lipid) diet. Measurements were taken $8 \mathrm{~h}$ after the last feeding. Glucose-6-phosphatase (g6pase), fructose 1,6-bisphosphatase (fbpase), and phosphoenolpyruvate carboxykinase (pepck) mRNA levels were measured using real-time quantitative RT-PCR. Results represent the mean \pm s.e.m $(n=6)$. Significance was determined using a two-way ANOVA $(P<0.05)$, followed by the Student-Newman-Keuls multiple comparison test. carbohydrate and lipid concentrations (Table 5): the highest TG and cholesterol levels were observed in fish fed the HCLL diet, regardless of strain.

\section{Gene Expression Levels}

The transcription levels of glut2 $(P=0.040), g k(P=0.012)$, and $6 p f k(P=0.005)$ in the liver were lower in fish of both strains fed the low carbohydrate diet as compared to fish fed the other two diets (Figure 1A), but the varying dietary carbohydrate and lipid level had no impact on the expression of genes involved in glucose transport and glycolysis in the muscle of either strain (Figure 1B). The transcription levels of genes associated with glycolysis were higher in both the liver $(g k, P=0.023$; $6 p f k, P=$ $0.001)$ and the skeletal muscle ( $6 p f k, P=0.002 ; p k, P=0.002)$ of the F strain as compared to the A strain, with the exception of $p k$ transcription in the liver and $h k 2$ transcription in the muscle. The mRNA expression levels of the hepatic gluconeogenesis enzymes g6pase, fbpase, and pepck were not affected by the varying dietary carbohydrate and lipid concentration in either strain (Figure 2).

In both strains, transcriptional factor srebp $1-c$ was upregulated in the liver $(P=0.004$, Figure 3A) and the skeletal muscle $(P=$ 0.001 , Figure 3B) with the increasing concentration of dietary carbohydrate and decreasing concentration of lipid. Similarly, mRNA expression of acly in the liver $(P=0.001)$ and acc in the muscle $(P<0.001)$ of both strains increased with the increasing concentration of dietary carbohydrate and decreasing concentration of lipid. The expression of acly in the muscle of the F strain was higher $(P=0.031)$ than in the A strain, irrespective of diet. However, the transcriptional expression of acc in the liver and fas in both tissues were not affected by variations among treatments.

The mRNA expression levels of genes associated with hepatic lipolysis $(h s l$ and $l p l)$ and fatty acid oxidation (ppar $\alpha$ and $c p t 1 a)$ did not vary with diet in either strain (Figure 4A). However, as compared to A strain, $h s l$ and ppara were more transcriptionally abundant in the muscle ( $h s l, P<0.001$; ppara, $P=0.001$ ) of the F strain, and aco3 was more transcriptionally abundant in the liver $(P=0.013)$ and the muscle $(P<0.001)$ of the $\mathrm{F}$ strain (Figure 4B). The mRNA expression of atgl was higher in the muscle of the F strain as compared to the A strain across all diets except for LCHL. In contrast, atgl expression in the liver of the A strain was higher $(P=0.016)$ than in the liver of the $\mathrm{F}$ strain. Thus, $h s l$ was downregulated $(P=0.012)$ in the muscle and aco3 was downregulated $(P=0.015)$ in the liver of fish fed the LCHL diet, irrespective of genotype.

\section{Enzyme Activity}

Dietary carbohydrate and lipid affected the activity levels of enzymes associated with glycolysis (HK, $P=0.040)$ and lipid uptake (LPL, $P=0.001$ ) in the liver irrespective of genotype (Table 6). The lowest HK and LPL activities were observed in the fish fed LCHL diet. Similarly, the lowest concentrations of enzymes involved in de novo fatty acid synthesis (ACC and FAS) were also found in the fish fed the LCHL diet. Neither genotype nor the dietary carbohydrate and lipid affected PK, PEPCK and HL activity levels. A strain displayed higher $(P=0.039)$ levels of LPL activity than the F strain, irrespective of diet. 
A
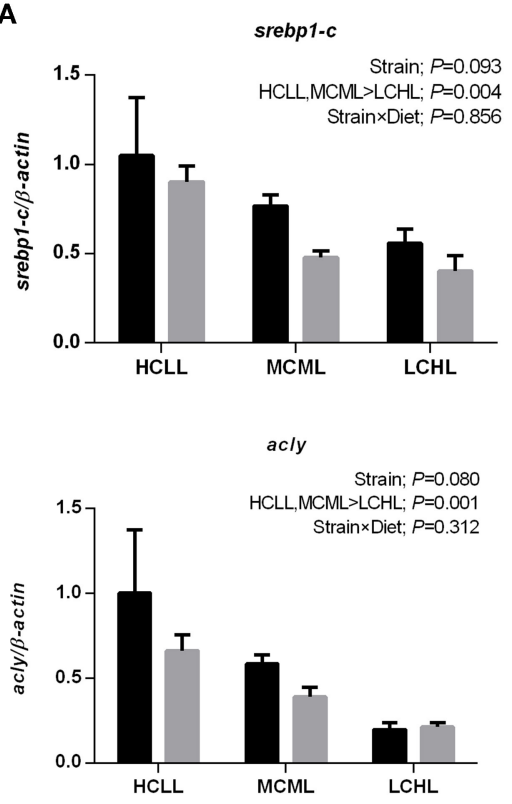

acc

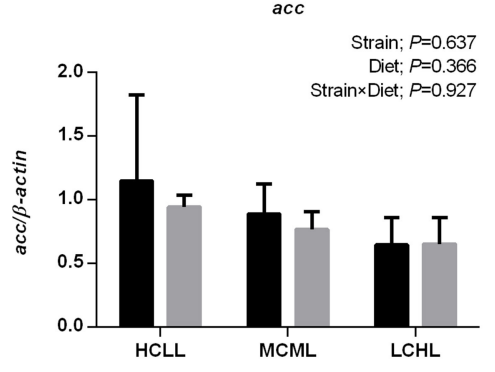

fas

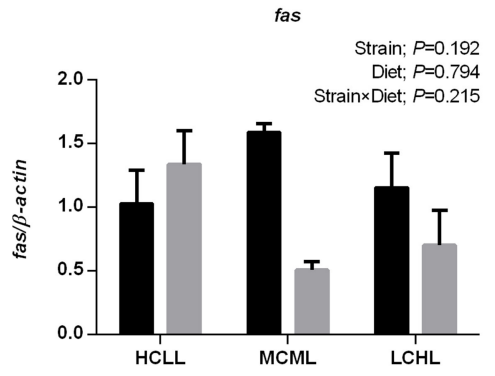

B

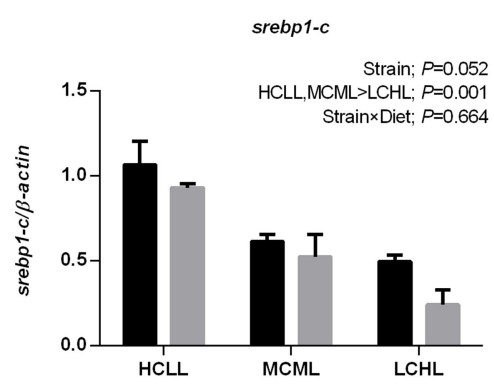

acly
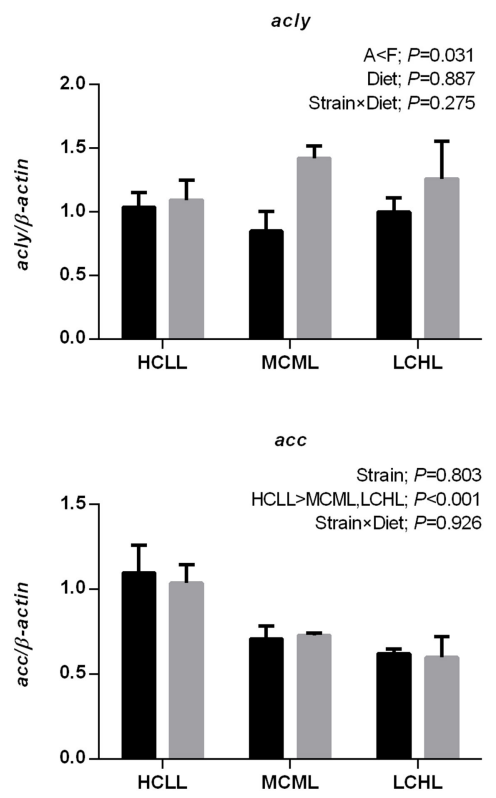

fas

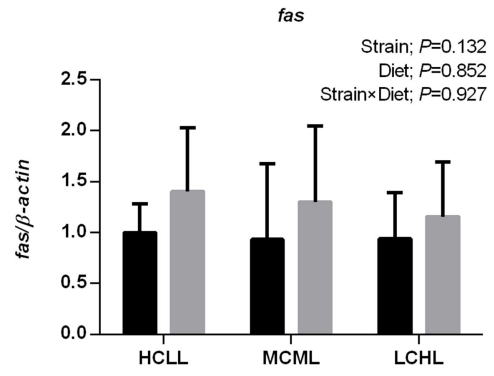

FIGURE 3 | Gene expression levels of selected enzymes and transcription factors associated with nicotinamide adenine dinucleotide phosphate (NADPH) generation and lipogenesis in the liver (A) and muscle (B) of the A strain (black bars) and the F strain (gray bars) fed the HCLL (High Carbohydrate Low Lipid, 45\% carbohydrate, 2\% lipid), MCML (Medium Carbohydrate Medium Lipid, 30\% carbohydrate, 8\% lipid), or LCHL (Low Carbohydrate High Lipid, 15\% carbohydrate, 14\% lipid) diet. Measurements were taken $8 \mathrm{~h}$ after the last feeding. Sterol regulatory element binding protein 1- c (srebp1-c), ATP citrate lyase (acly), acetyl-CoA carboxylase (acc), and fatty acid synthase (fas) mRNA levels were measured using real-time quantitative RT-PCR. Results represent the mean \pm s.e.m ( $n=6$ ). Significance was determined using a two-way ANOVA $(P<0.05)$, followed by the Student-Newman-Keuls multiple comparison test.

\section{DISCUSSION}

\section{Dietary Effects}

High concentrations of carbohydrate are known to increase HSI in fish $(21,42)$. Here, higher $(P=0.022)$ HSIs were observed in both strains of gibel carp fed higher concentrations of dietary carbohydrate, consistent with results for blunt snout bream (Megalobrama amblycephala) $(42,43)$, European sea bass (Dicentrarchus labrax) (44), and rainbow trout (Oncorhynchus mykiss) (21). Excess carbohydrates are converted into simple sugars by digestion, then into pyruvate by glycolysis; pyruvate is then either oxidized for energy or channeled into pathways for fatty acids synthesis (lipogenesis) when energy is available (45). It was therefore unsurprising that the highest levels of 
A
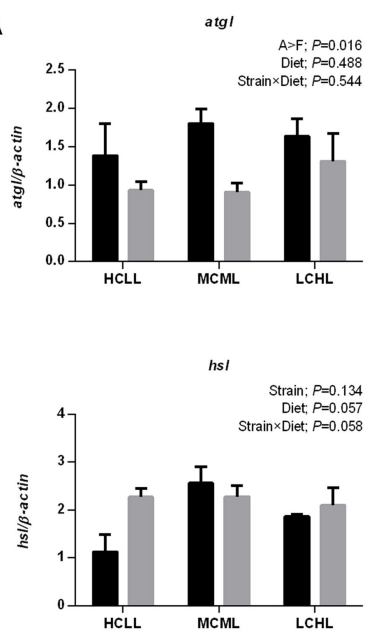

$|p|$
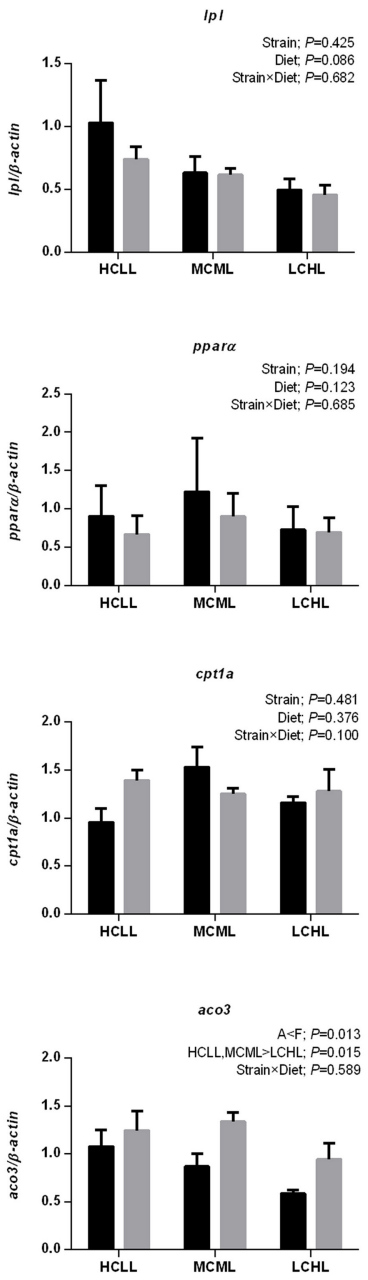

B

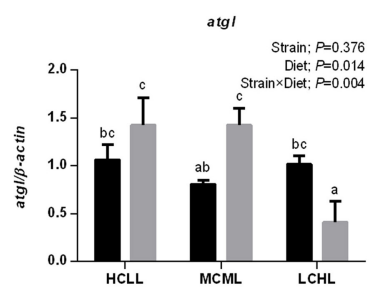

hsl

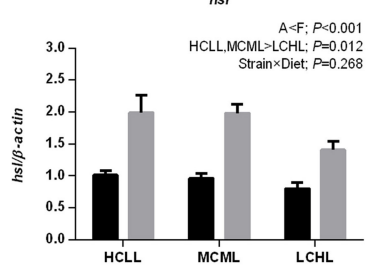

$|p|$
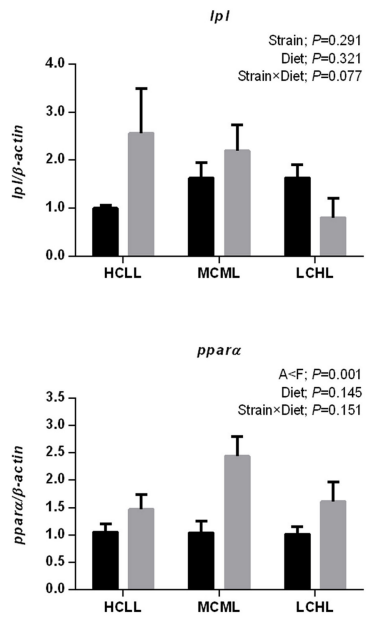

cpt1a

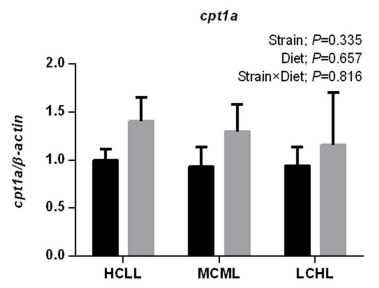

aco 3

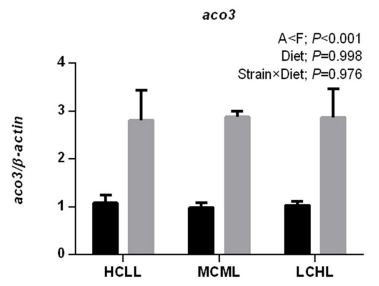

FIGURE 4 | Gene expression of selected enzymes associated with lipolysis and fatty acid oxidation in the liver (A) and muscle (B) of A strain (black bars) and F strain (gray bars) fed the HCLL (High Carbohydrate Low Lipid, 45\% carbohydrate, 2\% lipid), MCML (Medium Carbohydrate Medium Lipid, 30\% carbohydrate, 8\% lipid), or LCHL (Low Carbohydrate High Lipid, 15\% carbohydrate, 14\% lipid) diet. Measurements were taken $8 \mathrm{~h}$ after the last feeding. Lipolysis, including the expression of adipose triglyceride lipase (atgl), hormone-sensitive lipase (hs/), and lipoprotein lipase (/p/) were measured using real-time quantitative RT-PCR. And fatty acid oxidation, as indicated by the expression of peroxisome proliferator-activated receptor alpha (ppar $\alpha$ ), carnitine palmitoyl transferase $1 \mathrm{~A}$ (cpt1a), and acyl-CoA oxidase 3 (aco3) were also measured using the same methods. Results represent the mean \pm s.e.m $(n=6)$. Significance was determined using a two-way ANOVA $(P<0.05)$, followed by the Student-Newman-Keuls multiple comparison test. 
TABLE 6 | Effects of dietary carbohydrate and lipid levels on the activity levels or concentrations of enzymes involved in carbohydrate and lipid metabolism in two strains of gibel carp.

\begin{tabular}{|c|c|c|c|c|c|c|c|c|}
\hline Diet & Strain & HK (U/gprot) ${ }^{1}$ & P (U/gprot) ${ }^{2}$ & PEPCK (U/mgprot) ${ }^{3}$ & HL (U/mgprot) ${ }^{4}$ & LPL (U/mgprot) ${ }^{5}$ & ACC (ng/mgprot) ${ }^{6}$ & FAS (ng/mgprot) ${ }^{7}$ \\
\hline \multirow[t]{2}{*}{ HCLL } & A & $7.63 \pm 2.06$ & $115.6 \pm 18.42$ & $5.57 \pm 1.33$ & $1.98 \pm 0.20$ & $2.15 \pm 0.39$ & $0.32 \pm 0.08$ & $3.26 \pm 0.79$ \\
\hline & $\mathrm{F}$ & $8.63 \pm 3.69$ & $99.84 \pm 9.83$ & $4.33 \pm 0.47$ & $1.59 \pm 0.17$ & $1.92 \pm 0.32$ & $0.31 \pm 0.05$ & $4.09 \pm 0.81$ \\
\hline \multirow[t]{2}{*}{ MCML } & A & $7.91 \pm 6.29$ & $72.05 \pm 15.41$ & $3.96 \pm 0.27$ & $1.77 \pm 0.47$ & $2.20 \pm 0.22$ & $0.28 \pm 0.04$ & $4.70 \pm 1.51$ \\
\hline & $\mathrm{F}$ & $13.6 \pm 7.15$ & $102.49 \pm 11.46$ & $4.52 \pm 0.22$ & $1.97 \pm 0.91$ & $1.15 \pm 0.09$ & $0.26 \pm 0.04$ & $4.05 \pm 0.49$ \\
\hline \multirow[t]{2}{*}{ LCHL } & A & $6.58 \pm 1.97$ & $88.18 \pm 25.41$ & $3.79 \pm 0.39$ & $0.86 \pm 0.14$ & $0.97 \pm 0.15$ & $0.09 \pm 0.02$ & $1.51 \pm 0.30$ \\
\hline & $\mathrm{F}$ & $6.59 \pm 2.64$ & $70.26 \pm 19.12$ & $3.57 \pm 0.80$ & $1.29 \pm 0.42$ & $0.86 \pm 0.26$ & $0.15 \pm 0.02$ & $1.97 \pm 0.35$ \\
\hline \multicolumn{9}{|c|}{ MEANS OF MAIN EFFECT } \\
\hline \multicolumn{9}{|c|}{ Diet } \\
\hline \multicolumn{2}{|c|}{ HCLL } & $8.13 \pm 1.41^{Y}$ & & & & $2.04 \pm 0.19^{Y}$ & $0.31 \pm 0.03^{Y}$ & $3.67 \pm 0.57^{Y}$ \\
\hline \multicolumn{2}{|c|}{ MCML } & $10.75 \pm 1.50^{Y}$ & & & & $1.68 \pm 0.18^{Y}$ & $0.27 \pm 0.03^{Y}$ & $4.37 \pm 0.57^{Y}$ \\
\hline \multicolumn{2}{|c|}{ LCHL } & $6.59 \pm 1.63^{X}$ & & & & $0.91 \pm 0.19^{X}$ & $0.12 \pm 0.03^{X}$ & $1.74 \pm 0.57^{X}$ \\
\hline \multicolumn{9}{|c|}{ Strain } \\
\hline \multicolumn{2}{|c|}{ A } & & & & & $1.77 \pm 0.15^{\mathrm{B}}$ & & \\
\hline \multicolumn{2}{|c|}{$\mathrm{F}$} & & & & & $1.31 \pm 0.15^{\mathrm{A}}$ & & \\
\hline \multirow[t]{3}{*}{$\boldsymbol{P}$} & Strain & 0.220 & 0.940 & 0.550 & 0.840 & 0.039 & 0.808 & 0.754 \\
\hline & Diet & 0.040 & 0.240 & 0.130 & 0.205 & 0.001 & $<0.001$ & 0.009 \\
\hline & $S \times D$ & 0.390 & 0.260 & 0.350 & 0.697 & 0.154 & 0.668 & 0.641 \\
\hline
\end{tabular}

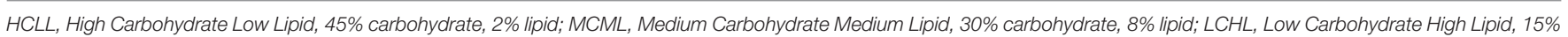
carbohydrate, $14 \%$ lipid.

${ }^{1} \mathrm{HK}$, hexokinase.

${ }^{2} \mathrm{PK}$, pyruvate kinase.

${ }^{3}$ PEPCK, phosphoenolpyruvate carboxykinase.

${ }^{4} H L$, hepatic lipase.

${ }^{5} L P L$, lipoprotein lipase.

${ }^{6}$ ACC, acetyl-CoA carboxylase.

${ }^{7}$ FAS, fatty acid synthase.

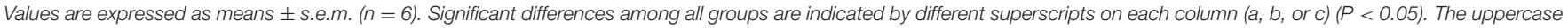
letters $A$ and $B$ represent significant differences between strains; and the uppercase letters $X, Y$, and $Z$ represent significant differences among diets $(P<0.05)$.

hepatic crude lipids and triglycerides were observed in the HCLL-fed fish across both strains. This result may also explain the higher HSIs identified in these groups. The higher LRE levels observed in the HCLL- and MCML-fed groups suggested that carbohydrates might have been converted into lipids and then accumulated in both strains of gibel carp. The lower LRE levels observed in fish fed the LCHL diet might be because more dietary lipids were used for energy in these fish, decreasing lipid retention efficiency. Thus, the dietary carbohydrate and lipid concentrations played a vital role in nutrient retention, despite the interactions identified between diet and genotype.

Crude lipid content did not vary among diets in either strain of gibel carp. Lipid accumulation is a complex process involving lipid transport, uptake, synthesis, and catabolism (46). In vertebrates like fish, lipoproteins are the primary carriers of lipids through the circulatory system of vertebrates (46). Lipoproteins deliver endogenous and dietary lipids to peripheral tissues, where LPL hydrolyzes the TGs of TG-rich lipoproteins (chylomicrons and VLDL) (47). Fatty acids are then released and taken up by the tissues for oxidation or storage (14). Although the mRNA expression of $l p l$ did not vary in the liver or muscle of either strain, the elevated hepatic LPL activity observed in gibel carp fed with the HCLL and MCML diets implied an increase in liver tissue fatty acid uptake in these fish. In addition, lipogenesis potential was increased in the fish fed the HCLL diet, as indicated by the increased abundance of srebp1-c and acly transcripts in the liver and the increased abundance of srebp1-c and acc in the muscle. Concurrent with this, higher ACC and FAS levels were observed in HCLL and MCML, confirmed that enhanced lipogenesis in these two groups. Such increases might lead to the accumulation of crude lipids and triglycerides in the livers of these fish. Moreover, the HCLL and MCML diets also promoted lipolysis (i.e., increased $h s l$ transcription) in the muscle and fatty acid oxidation (i.e., increased aco3 transcription) in the liver. Thus, increased lipolysis, lipid uptake (i.e., LPL activity) and the induction of the lipogenesis pathway, was observed in both strains fed the HCLL and MCML diets. This result partially explained the similarity in body lipid content across the two strains of gibel carp and across the different dietary carbohydrate and lipid.

Higher concentrations of carbohydrates increased glucose transportation rate and glycolysis potential, as indicated by the upregulation of the hepatic genes glut2, $g k$, and $6 p f k$ in both strains of gibel carp. This was consistent with results in rainbow trout (Oncorhyncus mykiss), and gilthead sea bream (Sparus aurata), where the expression of $g k$ (the first step of 
glycolysis) was dramatically upregulated by a carbohydraterich diet (48). In line with this, HK activity in the liver was induced $(P=0.040)$ in fish fed HCLL and MCML diets. In fish, muscle represents approximately half of the body mass, and thus plays an important role in glucose homeostasis (49). Unlike the liver, glucose transport and glycolysis in the fish muscle were unaffected by the dietary concentrations of carbohydrate and lipid. This indicated that the liver might be the first organ to respond to variations in the dietary carbohydrate and lipid in gibel carp. Unlike in rainbow trout, both mRNA and activity levels of enzymes involved in gluconeogenesis were unaltered in both A strain and F strain fed a high carbohydrate diet (27). Plasma glucose levels were unaffected by ingestion of a high carbohydrate diet, suggesting that both gibel carp strains were able to efficiently regulate glycemia. Overall, the stable plasma glucose levels might be due to the increased lipogenesis potential of the liver and the muscle, as well as the lack of alteration in gluconeogenesis.

\section{Genotype Effect}

Here, we found that genetic background affected lipid metabolism. Plasma triglyceride content was higher in the F strain than in the A strain, irrespective of diet, despite the interactions $(P=0.013)$ identified between genotype and diet. Indeed, NEFA $(P<0.001)$ and LDL-C $(P=0.016)$ levels were higher in the $\mathrm{F}$ strain as compared to the A strain. With respect to lipogenesis, acly was upregulated $(P=0.031)$ in the muscle of the $\mathrm{F}$ strain as compared to the A strain, irrespective of diet. As compared to the A strain, the F strain had higher $(P=0.016)$ levels of plasma LDL-C; increased $h s l$ and ppar $\alpha$ transcription in the muscle; and increased aco 3 transcription in both liver and muscle. This implied that, in the F strain, transportation of hepatic lipids to peripheral tissues was better, providing energy via the fatty acid $\beta$-oxidation pathway after hydrolyzation. As compared to the F strain, the A strain had a higher atgl expression in the liver and lower hsl expression in the muscle, suggesting that the triglyceride hydrolyzation limits in the liver and muscle were not the same between strains. However, LPL activity was higher in the A strain than in the F strain, suggesting better hydrolization ability of triacylglycerols in chylomicrons and VLDL in this strain (50).

We found that the growth performance of A strain was better than that of F strain, irrespective of diet. The higher $(P<0.001)$ FR observed in A strain as compared to $F$ strain might be the major factor responsible for the superior growth performance of this strain. However, the glucose uptake of F strain was better than that of A strain, as indicated by the higher expression levels of glut2 $(P=0.003)$ in the liver and glut4 $(P<0.001)$ in the muscle. Furthermore, the transcriptional levels of $g k(P=0.023)$ and $6 p f k(P<0.001)$ in the liver, and $6 p f k(P=0.002)$ and $p k(P$ $=0.002)$ in the muscle of $F$ strain were higher than in A strain, indicating that $\mathrm{F}$ strain had a greater glycolysis potential than A strain.

\section{Genotype-Diet Interactions}

The interactions between genotype and diet in gibel carp were not identified on growth performance, proximate composition, or appearance. However, the interactions between genotype and diet existed on nutrient retention [i.e., $\operatorname{PRE}(P<0.001)$ and LRE $(P=$ 0.026)]. Higher LRE levels were observed in the F strain, implying greater lipid accumulation in this strain than in the A strain. Interestingly, dietary carbohydrate level was more important for lipid accumulation than dietary lipid concentration. The energy supplied by dietary lipids has been shown to effectively spare protein in many fish species (5). In blunt snout bream (Megalobrama amblycephala), the activity levels of growth and digestive enzymes increased when dietary lipid content increased from 40 to $70 \mathrm{~g} \mathrm{~kg}^{-1}$, reducing the proportion of dietary protein catabolized for energy (13). Thus, increasing lipid contents may provide adequate energy for the $\mathrm{F}$ strain, reducing protein catabolism and contributing to the higher PRE observed in the F strain fed the LCHL diet. The superior feed utilization and the higher protein retention efficiency of the F strain fed a highlipid diet suggested that the F strain utilized lipids better than the A strain.

In conclusion, dietary carbohydrate and lipid concentration interacted with genotype to some extent. For example, although a high-carbohydrate diet stimulated glycolysis and lipogenesis in both gibel carp strains, the F strain more efficiently utilized dietary lipids than the A strain. This was indicated by the higher levels of plasma lipids and lipoproteins, increased fatty acid oxidation potential in the muscle, and improved nutrient retention in the F strain carp fed a high-lipid diet. Glucose uptake and glycolysis potential were also greater in the F strain as compared to the A strain. Thus, genetic selection might help to breed new gibel carp strains with improved carbohydrate and lipid utilization abilities.

\section{DATA AVAILABILITY}

All datasets generated for this study are included in the manuscript and/or the supplementary files.

\section{ETHICS STATEMENT}

The experimental protocol was approved by the ethics committee of the Institute of Hydrobiology, Chinese Academy of Sciences.

\section{AUTHOR CONTRIBUTIONS}

HoL, JJ, and SX designed the study. HoL performed all the experiments and wrote the paper. WX, XZ, YY, DH, HaL, and SX gave suggestions about paper writing. JJ revised the paper.

\section{FUNDING}

This work was financially supported by the National Key R\&D Program of China (2018YFD0900605; 2018YFD0900400), the China Agriculture Research System (CARS-45-09), Special Fund for Technical Innovation of Hubei Province 
(2017ABA061), the National Natural Science Foundation of China (31672670; 31602174), and Major Science and Technology Program for Water Pollution Control and Treatment (2017ZX07203001; 2017ZX07603005).

\section{REFERENCES}

1. Han D, Shan XJ, Zhang WB, Chen YS, Wang QY, Li ZJ, et al. A revisit to fishmeal usage and associated consequences in Chinese aquaculture. Rev Fish Sci. (2016) 10:493-507. doi: 10.1111/raq.12183

2. Hardy RW. Utilization of plant proteins in fish diets: effects of global demand and supplies of fishmeal. Aquacult Res. (2010) 41:770-6. doi: 10.1111/j.1365-2109.2009.02349.x

3. Hemre GI, Mommsen TP, Krogdahl Å. Carbohydrates in fish nutrition: effects on growth, glucose metabolism and hepatic enzymes. Aquacult Nutr. (2015) 8:175-94. doi: 10.1046/j.1365-2095.2002.00200.x

4. Stone DAJ. Dietary carbohydrate utilization by fish. Rev Fish Sci. (2003) 11:337-69. doi: 10.1080/10641260390260884

5. Watanabe T. Strategies for further development of aquatic feeds. Fish Sci. (2002) 68:242-52. doi: 10.1046/j.1444-2906.2002.00418.x

6. Furuichi M, Yone Y. Change of blood sugar and plasma insulin levels of fishes in glucose tolerance test. Bull Jpn Soc Sci Fish. (1981) 47:761-4. doi: $10.2331 /$ suisan.47.761

7. Arnesen P, Krogdahl Å. Crude and pre-extruded products of wheat as nutrient sources in extruded diets for Atlantic salmon (Salmo salar, L) grown in sea water. Aquaculture. (1993) 118:105-17. doi: 10.1016/0044-8486(93)90284-6

8. Wilson RP. Utilization of dietary carbohydrate by fish. Aquaculture. (1994) 124:67-80. doi: 10.1016/0044-8486(94)90363-8

9. Gao W, Liu YJ, Tian LX, Mai KS, Liang GY, Yang HJ, et al. Effect of dietary carbohydrate-to-lipid ratios on growth performance, body composition, nutrient utilization and hepatic enzymes activities of herbivorous grass carp (Ctenopharyngodon idella). Aquacult Nutr. (2010) 16:327-33. doi: $10.1111 / j .1365-2095.2009 .00668 . x$

10. Li XF, Liu WB, Lu KL, Xu WN, Wang Y. Dietary carbohydrate/lipid ratios affect stress, oxidative status and non-specific immune responses of fingerling blunt snout bream, Megalobrama amblycephala. Fish Shellish Immunol. (2012) 33:316-23. doi: 10.1016/j.fsi.2012.05.007

11. Polakof S, Panserat S, Soengas JL, Moon TW. Glucose metabolism in fish: a review. J Comp Physiol B. (2012) 182:1015-45. doi: 10.1007/s00360-012-0658-7

12. Lin YH, Shiau SY. Dietary lipid requirement of grouper, Epinephelus malabaricus, and effects on immune responses. Aquaculture. (2003) 225:24350. doi: 10.1016/S0044-8486(03)00293-X

13. Li XF, Jiang YY, Liu WB, Ge XP. Protein-sparing effect of dietary lipid in practical diets for blunt snout bream (Megalobrama amblycephala) fingerlings: effects on digestive and metabolic responses. Fish Physiol Biochem. (2012) 38:529-41. doi: 10.1007/s10695-0119533-9

14. Lu KL, Xu WN, Li XF, Liu WB, Wang LN, Zhang CN. Hepatic triacylglycerol secretion, lipid transport and tissue lipid uptake in blunt snout bream (Megalobrama amblycephala) fed high-fat diet. Aquaculture. (2013) 408409:160-8. doi: 10.1016/j.aquaculture.2013.06.003

15. Sáez-Royuela M, Casado M, Celada JD, Carral JM, González-Rodríguez A. Effect of dietary lipid level on survival, growth performance and body composition of juvenile tench (Tinca tinca L.) fed practical diets. Aquaculture. (2015) 439:14-9. doi: 10.1016/j.aquaculture.2015.0 1.017

16. Honorato CA, Almeida LC, Dasilva Nunes C, Carneiro DJ, Moraes G. Effects of processing on physical characteristics of diets with distinct levels of carbohydrates and lipids: the outcomes on the growth of pacu (Piaractus mesopotamicus). Aquacult Nutr. (2010) 16:91-9. doi: $10.1111 / j .1365-2095.2008 .00644 . x$

17. Güm,üs E Ikiz. R. Effect of dietary levels of lipid and carbohydrate on growth performance, chemical contents and digestibility in rainbow trout, Oncorhynchus mykiss Walbaum, 1792. Pak Vet J. (2009) 29:59-63.

\section{ACKNOWLEDGMENTS}

The authors thank Mr. Guanghan Nie for his technical support with the research system.

Available online at: http://agris.fao.org/agris-search/search.do? recordID= PK2009000872

18. Li XF, Lu KL, Liu WB, Jiang GZ, Xu WN. Effects of dietary lipid and carbohydrate and their interaction on growth performance and body composition of juvenile blunt snout bream, Megalobrama amblycephala. Isr J Aquacult Bamidgeh. (2014) 66:931-8. http://evols.library.manoa.hawaii.edu/ bitstream/10524/49111/IJA_66.2014.931.Liu.pdf

19. Miao S, Nie Q, Miao H, Zhang W, Mai K. Effects of dietary carbohydrateto-lipid ratio on the growth performance and feed utilization of juvenile turbot (Scophthalmus maximus). J Ocean Univ China. (2016) 15:660-6. doi: 10.1007/s11802-016-2934-8

20. Erfanullah and Jafri AK. Effect of dietary carbohydrate-to-lipid ratio on growth and body composition of walking catfish (Clarias batrachus). Aquaculture. (1998) 161:159-68. doi: 10.1016/S0044-8486(97)00267-6

21. Brauge C, Medale F, Corraze G. Effect of dietary carbohydrate levels on growth, body composition and glycaemia in rainbow trout, Oncorhynchus mykiss, reared in seawater. Aquaculture. (1994) 123:109-20. doi: 10.1016/0044-8486(94)90123-6

22. Peres H, Oliva-Teles A. Effect of dietary lipid level on growth performance and feed utilization by European sea bass juveniles (Dicentrarchus labrax). Aquaculture. (1999) 179:325-34. doi: 10.1016/S0044-8486(99)00168-4

23. Boonanuntanasarn S, Kumkhong S, Yoohat K, Plagnesjuan E, Burel C, Marandel L, et al. Molecular responses of Nile tilapia (Oreochromis niloticus) to different levels of dietary carbohydrates. Aquaculture. (2018) 482:117-23. doi: 10.1016/j.aquaculture.2017.09.032

24. Ellis SC, Reigh RC. Effects of dietary lipid and carbohydrate levels on growth and body composition of juvenile red drum, Sciaenops ocellatus. Aquaculture. (1991) 97:383-94. doi: 10.1016/0044-8486(91)90330-A

25. Mazur CN, Higgs DA, Plisetskaya E, March BE. Utilization of dietary starch and glucose tolerance in juvenile chinook salmon (Oncorhynchus tshawytscha) of different strains in seawater. Fish Physiol Biochem. (1992) 10:303-13. doi: 10.1007/BF00004479

26. Blanc JM. Interaction between diet and genetic aptitude for weight and growth in juvenile rainbow trout, Oncorhynchus mykiss (Walbaum). Aquacult Res. (2002) 33:563-8. doi: 10.1046/j.1365-2109.2002.00679.x

27. Kamalam BS, Medale F, Kaushik S, Polakof S, Skiba-Cassy S, Panserat S. Regulation of metabolism by dietary carbohydrates in two lines of rainbow trout divergently selected for muscle fat content. J Exp Biol. (2012) 215:256778. doi: $10.1242 /$ jeb. 070581

28. Kamalam BS, Panserat S, Aguirre P, Geurden I, Fontagné-Dicharry S, Médale F. Selection for high muscle fat in rainbow trout induces potentially higher chylomicron synthesis and PUFA biosynthesis in the intestine. Comp Biochem Physiol Part A: Mol Integr Physiol. (2013) 164:417-27. doi: 10.1016/j.cbpa.2012.11.020

29. Morais S, Pratoomyot J, Taggart JB, Bron JE, Guy DR, Bell JG, et al. Genotypespecific responses in Atlantic salmon (Salmo salar) subject to dietary fish oil replacement by vegetable oil: a liver transcriptomic analysis. BMC Genomics. (2011) 12:255. doi: 10.1186/1471-2164-12-255

30. Gui JF, Zhou L. Genetic basis and breeding application of clonal diversity and dual reproduction modes in polyploid Carassius auratus gibelio. Sci China Life Sci. (2010) 53:409-15. doi: 10.1007/s11427-010-0092-6

31. Jin JY, Zhu XM, Han D, Yang YX, Liu HK, Xie SQ. Different regulation of insulin on glucose and lipid metabolism in 2 strains of gibel carp. Gen. Comp. Endocrinol. (2017) 246, 363-71. doi: 10.1016/j.ygcen.2017.01.012

32. Zhou L, Yang W, Gui JF. Genetic evidence for gonochoristic reproduction in gynogenetic silver crucian carp (Carassius auratus gibelio Bloch) as revealed by RAPD assays. J Mol Evol. (2000) 51:498. doi: 10.1007/s002390010113

33. Wang ZW, Zhu HP, Da W, Jiang FF, Wei G, Li Z, et al. A novel nucleocytoplasmic hybrid clone formed via androgenesis in polyploid gibel carp. BMC Res Notes. (2011) 4:1-13. doi: 10.1186/1756-0500-4-82 
34. Gao FX, Wang Y, Zhang QY, Mou CY, Li Z, Deng YS, et al. Distinct herpesvirus resistances and immune responses of three gynogenetic clones of gibel carp revealed by comprehensive transcriptomes. BMC Genomics. (2017) 18:56180. doi: 10.1186/s12864-017-3945-6

35. Jin JY, Yang YX, Zhu XM, Han D, Liu HK, Xie SQ. Effects of glucose administration on glucose and lipid metabolism in two strains of gibel carp (Carassius gibelio). Gen Comp Endocrinol. (2018) 267:18-28. doi: 10.1016/j.ygcen.2018.05.023

36. Li HY, Xu WJ, Jin JY, Yang YX, Zhu XM, Han D, et al. Effects of starvation on glucose and lipid metabolism in gibel carp (Carassius auratus gibelio var. CAS III) Aquaculture. (2018) 496:166-75. doi: 10.1016/j.aquaculture.2018.07.015

37. Xie SQ, Zhu XM, Cui YB, Yang YX. Utilization of several plant proteins by gibel carp (Carassius auratus gibelio). J Appl Ichthyol. (2001) 17:70-6. doi: 10.1046/j.1439-0426.2001.00275.x

38. AOAC. (2003). Official Methods of Analysis of the Association of Official Analytical Chemists, 17th edn. Arlington, TX: AOAC.

39. Folch J, Lees M, Sloane Stanley GH. A simple method for the isolation and purification of total lipids from animal tissues. $J$ Biol Chem. (1957) 226:497-509.

40. Christie WW. Lipid Analysis. Pergamon, Oxford: Headington Hill Hall (1982).

41. Pfaffl MW. A new mathematical model for relative quantification in real-time RT-PCR. Nucleic Acids Res. (2001) 29:e45. doi: 10.1093/nar/29.9.e45

42. Zhou CP, Ge XP, Liu B, Xie J, Xu P, Zhou QL, et al. Effect of dietary carbohydrate level on growth performance, blood chemistry, hepatic enzyme activity, and growth hormone gene expression in Wuchang Bream (Megalobrama amblycephala). Isr J Aquacult Bamidgeh. (2013) 65:1-8. https://www.researchgate.net/publication/286280137_Effect_of_Dietary_ Carbohydrate_Level_on_Growth_Performance_Blood_Chemistry_Hepatic_ Enzyme_Activity_and_Growth_Hormone_Gene_Expression_in_Wuchang Bream_Megalobrama_amblycephala

43. Li XF, Wang Y, Liu WB, Jiang GZ, Zhu J. Effects of dietary carbohydrate/lipid ratios on growth performance, body composition and glucose metabolism of fingerling blunt snout bream Megalobrama amblycephala. Aquacult Nutr. (2013) 19:701-8. doi: 10.1111/anu.12017

44. Moreira IS, Peres H, Couto A, Enes P, Olivateles A. Temperature and dietary carbohydrate level effects on performance and metabolic utilisation of diets in European sea bass (Dicentrarchus labrax) juveniles. Aquaculture. (2008) 274:153-60. doi: 10.1016/j.aquaculture.2007.11.016

45. Uyeda K, Repa JJ. Carbohydrate response element binding protein, ChREBP, a transcription factor coupling hepatic glucose utilization and lipid synthesis. Cell Metab. (2006) 4:107-10. doi: 10.1016/j.cmet.2006. 06.008

46. Yan J, Liao K, Wang T, Mai KS, Xu W, Ai QH. Dietary lipid levels influence lipid deposition in the liver of large yellow croaker (Larimichthys crocea) by regulating lipoprotein receptors, fatty acid uptake and triacylglycerol synthesis and catabolism at the transcriptional level. PLoS ONE. (2015) 10:e0129937. doi: 10.1371/journal.pone.01 29937

47. Babin PJ, Vernier JM. Plasma lipoproteins in fish. $J$ Lipid Res. (1989) 30:467-89.

48. Panserat S, Médale F, Blin C, Brèque J, Vachot C, Plagnes-Juan E, et al. Hepatic glucokinase is induced by dietary carbohydrates in rainbow trout (Oncorhyncus mykiss), gilthead seabream (Sparus aurata) and common carp (Cyprinus carpio). Am J Physiol: Regul Integr Comp Physiol. (2000) 278:R11641170. doi: 10.1152/ajpregu.2000.278.5.R1164

49. Moon TW. Glucose intolerance in teleost fish: fact or fiction? Comp Biochem Physiol Part B. (2001) 129:243-9. doi: 10.1016/S1096-4959(01)0 0316-5

50. Tocher DR. Metabolism and functions of lipids and fatty acids in teleost fish. Rev Fish Sci. (2003) 11:107-84. doi: 10.1080/713610925

Conflict of Interest Statement: The authors declare that the research was conducted in the absence of any commercial or financial relationships that could be construed as a potential conflict of interest.

Copyright (c) $2019 \mathrm{Li}, \mathrm{Xu}$, Jin, Zhu, Yang, Han, Liu and Xie. This is an open-access article distributed under the terms of the Creative Commons Attribution License (CC BY). The use, distribution or reproduction in other forums is permitted, provided the original author(s) and the copyright owner(s) are credited and that the original publication in this journal is cited, in accordance with accepted academic practice. No use, distribution or reproduction is permitted which does not comply with these terms. 